\title{
Fibra na ração de crescimento e seus efeitos no desempenho de poedeiras nas fases de crescimento e postura
}

\author{
Nádia de Melo Braz ${ }^{1}$, Ednardo Rodrigues Freitas ${ }^{2}$, Roseane Madeira Bezerra ${ }^{1}$, Carlos \\ Eduardo Braga Cruz ${ }^{3}$, Nadja Naiara Pereira Farias ${ }^{3}$, Nemuel Muniz da Silva ${ }^{3}$, Newton Lima Sá ${ }^{3}$, \\ Regina Patrícia de Souza Xavier ${ }^{3}$
}

1 Programa de Pós-graduação em Zootecnia, Departamento de Zootecnia, UFC.

2 Departamento de Zootecnia, UFC, Caixa Postal 12167, 60021-970, Fortaleza - CE.

${ }^{3}$ Curso de graduação em Zootecnia, Universidade Federal do Ceará (UFC), Caixa Postal 12167, 60021-970, Fortaleza - CE.

RESUMO - Objetivou-se com esta pesquisa avaliar os efeitos dos níveis de fibra em detergente neutro (FDN) das rações

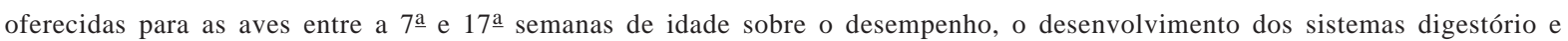
reprodutor, bem como os efeitos na maturidade sexual, no desempenho e na qualidade dos ovos na fase de postura. Foram distribuídas 1.296 aves em delineamento inteiramente casualizado em esquema fatorial $3 \times 2$, composto de três níveis de FDN e duas linhagens, com quatro repetições de 54 aves. Foram testados os níveis de 14,5; 16,5; e 18,5\% de FDN em aves leves e semipesadas. Ao final da fase de crescimento, as aves foram transferidas para o galpão de postura, mantendo o mesmo delineamento, composto por 14 aves por parcela. Não houve interação entre os níveis de FDN e as linhagens para as variáveis avaliadas. Na fase de crescimento, o aumento do nível de FDN reduziu o ganho de peso e o peso final, piorou a conversão alimentar e aumentou o peso dos intestinos. Na fase de postura, os níveis de FDN não influenciaram o desempenho das aves nem os constituintes e a qualidade dos ovos. Na fase de crescimento, as aves semipesadas apresentaram maior consumo, ganho de peso e peso final, melhor conversão alimentar, peso maior da moela e menor do fígado e do ovário. Na fase de postura, as aves leves foram mais precoces, apresentaram menor peso e massa de ovos, pior conversão alimentar, ovos com mais gema, menos albúmen, maior densidade específica e menores unidades Haugh. Independentemente da linhagem, o aumento do nível de FDN em rações para crescimento pode influenciar o desempenho das frangas, resultando em aves menos pesadas, sem influenciar a maturidade sexual, o desempenho e a qualidade dos ovos na fase de postura.

Palavras-chave: FDN, peso dos órgãos, poedeiras semipesadas e leves, qualidade dos ovos

\section{Fiber in growth ration and its effects on performance of laying hens during the growing and laying phases}

\begin{abstract}
The experiment was conducted to evaluate the effects of levels of neutral detergent fiber (NDF) of diets offered to the pullets between the $7^{\text {th }}$ and $17^{\text {th }}$ weeks of age on performance, development of the digestive and reproductive systems, as well as the effects on sexual maturity, performance and egg quality in laying phase, which was assessed until the $35^{\text {th }}$ week. A total of 1,296 pullets were distributed in a completely randomized design in a $3 \times 2$ factorial arrangement with four replicates of 54 birds. The levels of 14.5, 16.5 and 18.5\% NDF in light and semi-heavy birds were tested. At the end of the growth phase, the birds were transferred to the laying house, keeping the same experimental design, consisting of 14 birds per plot. There was no interaction between levels of NDF and the lines on the variables. In the growth phase, increasing the level of NDF reduced the weight gain and final weight, decreased feed conversion and increased the weight of the intestines. In the laying period, the levels of NDF did not affect significantly performance, the constituents or quality of eggs. In the growth phase, the semi-heavy birds had higher feed intake, weight gain and final weight, feed conversion, bigger weight of gizzard and lower weight of liver and ovary. In the laying period, the light birds were more precocious, had lower weight and egg mass, lower feed conversion, eggs with more yolk, less albumen, higher specific gravity and lower Haugh units. Regardless of lines, the increased level of NDF in diets for growth can influence the growth performance of pullets, resulting in fewer birds without heavy influence on sexual maturity, performance or egg quality in the laying phase.
\end{abstract}

Key Words: egg quality, NDF, organ weight, semi-heavy and light laying hens 


\section{Introdução}

Com os materiais genéticos de poedeiras utilizados atualmente, a formação da franga passou a ser considerada fundamental para seu posterior desempenho, como poedeira, na fase de produção. Nesse cenário, ao final da fase de crescimento, as aves devem apresentar peso corporal adequado, garantindo condições corporais para expressar todo o seu potencial genético.

Com o objetivo de obter peso corporal adequado, o manejo alimentar das aves tem merecido atenção, devido à influência direta da ingestão de nutrientes no ganho de peso. Talvez por isso, no manejo alimentar das poedeiras na fase de crescimento, tem sido comum o uso de programas de alimentação com três ou mais rações que se diferenciam pela redução dos níveis nutricionais, à medida que a ave cresce. Por outro lado, essa redução contribui para a adição de alimentos fibrosos nas rações, visando manter baixa densidade energética da ração e, assim, evitar o ganho de peso excessivo, principalmente para as aves de linhagens que apresentem maior capacidade de ingestão de ração (Scheideler et al., 1998).

Quanto ao conteúdo de fibra na ração de aves, tem-se recomendado para as aves jovens rações com pouca fibra para aumentar o consumo e melhorar o desempenho. Entretanto, essa concepção deve mudar, em função dos resultados das pesquisas, que têm sugerido que a inclusão moderada de fibra na ração pode ter benefícios no desenvolvimento do trato digestório e na eficiência alimentar na fase de crescimento (Scheideler et al., 1998; GonzálesAlvarado et al., 2007).

Vários métodos têm sido utilizados para quantificar a fração fibrosa dos alimentos para aves. Todavia, a determinação da fibra bruta e das fibras em detergente ácido (FDA) e em detergente neutro (FDN) é o método mais comum nos laboratório brasileiros. Entretanto, Jeraci \& Van Soest (1990) consideraram que a FDN pode ser uma medida importante para a caracterização da fibra das rações para aves em relação às outras duas.

Na literatura nacional, observa-se que pouca atenção tem sido dada aos efeitos da quantidade de fibra das rações de poedeiras em crescimento. Assim, realizou-se esta pesquisa com o objetivo de avaliar os efeitos dos níveis de fibra detergente neutro (FDN) das rações oferecidas para frangas de $7 \underline{a}$ a $17 \underline{a}$ semanas de idade e seus efeitos no desempenho, no desenvolvimento dos sistemas digestório e reprodutor de duas linhagens de poedeiras comerciais, bem como os efeitos subsequentes na maturidade sexual, no desempenho e na qualidade dos ovos na fase de postura.

\section{Material e Métodos}

Para condução do experimento, foram adquiridas 1.600 pintinhas de 1 dia, sendo metade de uma linhagem de poedeiras comerciais leves (Lohman LSL) e a outra metade de uma linhagem semipesada (Hy Line Brown).

Na fase inicial, até a sexta semana, as aves foram alojadas em galpão convencional para criação em piso e receberam manejo segundo recomendações contidas no manual de cada linhagem para a fase. Após a sexta semana, as aves foram pesadas e selecionadas para obtenção de parcelas experimentais com peso médio uniforme, segundo recomendações propostas por Sakomura \& Rostagno (2007).

$\mathrm{Na}$ condução do experimento, para a fase de crescimento, foram utilizadas 1.296 aves com 7 a 17 semanas de idade. As aves foram distribuídas em delineamento experimental inteiramente casualizado em esquema fatorial $3 \times 2$, composto de três níveis de FDN e duas linhagens com quatro repetições de 54 aves. Os níveis de FDN testados foram 14,$50 ; 16,50$ e $18,50 \%$.

Nesta fase, as aves foram alojadas em gaiolas de arame galvanizado, com $50 \mathrm{~cm} \times 50 \mathrm{~cm} \times 45 \mathrm{~cm}$. O número total de aves de cada parcela (54 aves) foi dividido de acordo com a capacidade da gaiola (9 aves/gaiola), totalizando 6 gaiolas por parcela. Cada gaiola dispunha de comedouro tipo calha em chapa galvanizada e bebedouro tipo nipple.

Diariamente, duas vezes ao dia, às 8 e às $16 \mathrm{~h}$, durante todo o período experimental, a temperatura e umidade relativa do ar dentro do galpão foram medidas com termômetro de máxima e mínima e psicrômetro, respectivamente. No final do experimento, foram calculadas as médias das temperaturas máximas e mínimas e os valores de umidade relativa do ar.

Para formulação das rações (Tabela 1), foram considerados os valores de composição dos alimentos propostos por Rostagno et al. (2005) e as exigências nutricionais das aves propostas nos manuais de manejo. Em razão das semelhanças entre os valores de exigências nutricionais propostas para cada fase de criação das linhagens utilizadas no experimento, utilizou-se a mesma ração para ambas as linhagens. As rações da fase experimental foram formuladas para ser isonutritivas, exceto quanto ao nível de FDN.

Para avaliar o desempenho, semanalmente foram pesadas as aves e as rações, para determinação do peso médio (g), do ganho de peso (g/ave), do consumo de ração (g/ave) e da conversão alimentar (g/g).

$\mathrm{Na}$ 17a semana, foram selecionadas duas aves com o mesmo peso médio da parcela. As aves foram sacrificadas por deslocamento cervical para retirada dos órgãos do trato digestório (moela, fígado e intestinos) e órgãos reprodutores 
Tabela 1 - Composição percentual e nutricional calculada das rações experimentais utilizadas para poedeiras comerciais na fase de crescimento e postura

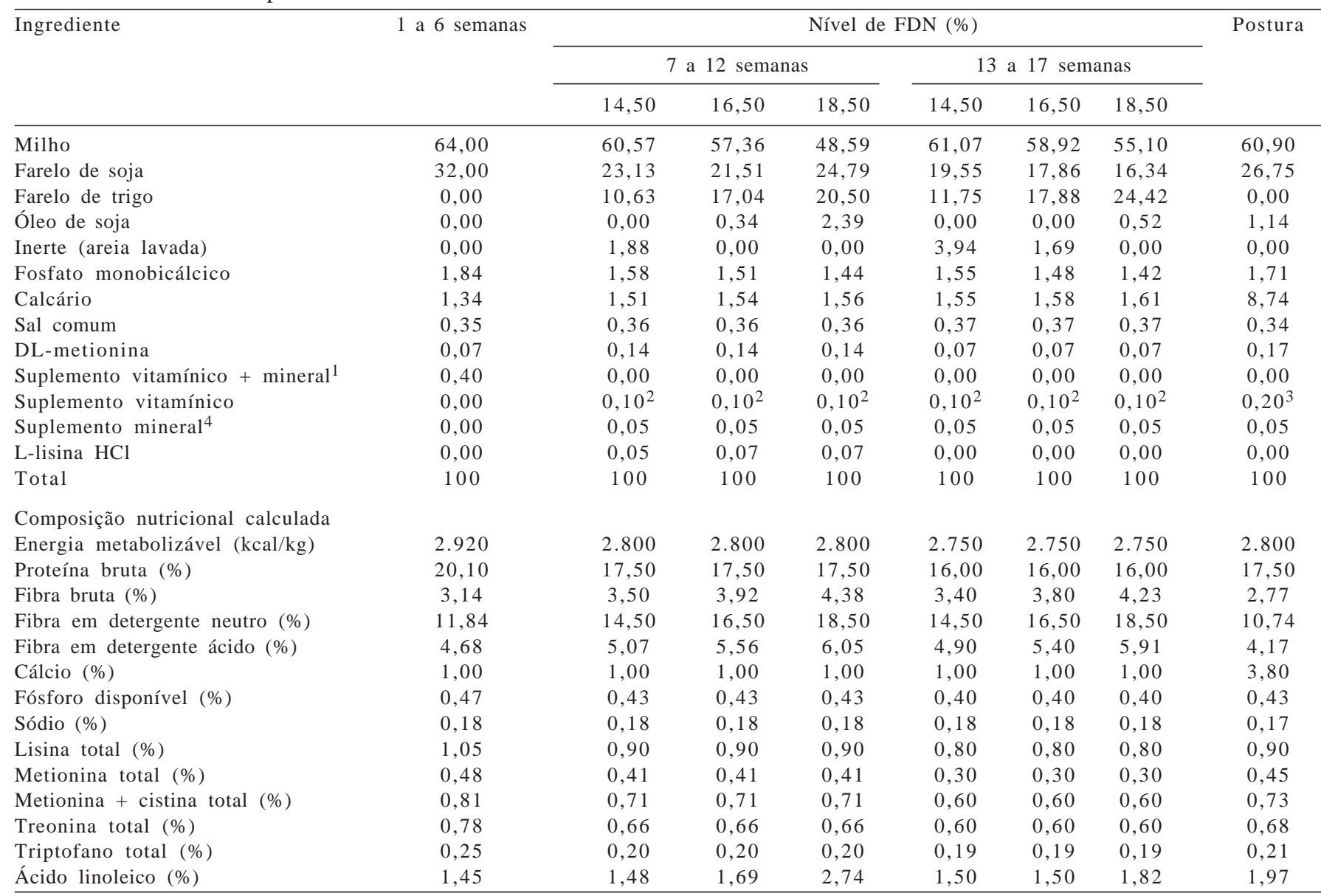

${ }^{1}$ Suplemento vitamínico mineral (composição por kg do produto): vit. A - 1.775.000 UI; vit. B12 - 2.280 mcg; vit. D3 - 450.000 UI; vit. E - 2.275 mg; vit. K - 325 mg; ácido fólico - $113 \mathrm{mg}$; niacina - $5.750 \mathrm{mg}$; piridoxina - $450 \mathrm{mg}$; colistina - $1.750 \mathrm{mg}$; roboflavina - $1.125 \mathrm{mg}$; tiamina - $450 \mathrm{mg}$; pantotenato de cálcio - $2.275 \mathrm{mg}$; colina - 66.000 ; biotina - 11,30 mg; antioxidante - $500 \mathrm{mg}$; silicato - $10.000 \mathrm{mg}$; cobalto - 25,00 mg; cobre - $2.500 \mathrm{mg}$; ferro - $6.250 \mathrm{mg}$; iodo - $260 \mathrm{mg}$; manganês - $13.000 \mathrm{mg}$; metionina 225 g; selênio - 45,00 mg; zinco - $11.100 \mathrm{mg}$.

2 Suplemento vitamínico crescimento (composição por kg do produto): vit. A - 6.000 .000 UI; vit. D3 - 2.000 .000 UI; vit. E - 12.000 mg; vit. K3 - 2.000 mg; vit. B1 - 2.200 UI; vit. B2 - 5.000; vit B6 - 2.300 mg; vit. B12 - 12.000 mcg; niacina - 28.000 mg; ácido fólico - 600 mg; ácido pantotênico - 11.000 mg; antioxidante - 15 mg; biotina - 20 mg; selênio - $200 \mathrm{mg}$.

${ }^{3}$ Suplemento vitamínico postura (composição por kg do produto): vit. A - 7.000.000 UI; vit. D3 - 2.000 .000 UI; vit. E - 5.000 mg; vit. K3 - 1.000 mg; vit. B1 - 1.000 UI; vit. B2 - 3.000; vit B6 - 502 mg; vit. B12 - 10.000 mcg; niacina - 15.000 mg; ácido fólico - 500 mg; ácido pantotênico - 8.000 mg; antioxidante - 15 mg; selênio - 300 mg.

${ }^{4}$ Suplemento mineral (composição por kg do produto): manganês - 130.000 mg; zinco - 100.000 mg; ferro - 80.000 mg; cobre - 24.000 mg; iodo - 2.000 g; veículo q.s.p.

(ovário e oviduto). Os intestinos e a moela foram devidamente esvaziados para determinação do peso dos órgãos vazios. Todos os órgãos foram pesados em balança de precisão 0,01 g e os dados de peso expressos em porcentagem do peso corporal.

Ao final da fase de crescimento, as aves foram transferidas para o galpão de postura, mantendo-se o mesmo delineamento experimental utilizado na fase de crescimento, onde cada parcela era composta por 14 aves. O período experimental na fase de postura se estendeu até a $35^{\underline{a}}$ semana de idade e foi dividido em períodos de 28 dias.

As aves foram distribuídas em gaiolas de arame $(25 \mathrm{~cm}$ $\times 45 \mathrm{~cm} \times 40 \mathrm{~cm}$ ) equipadas com comedouro linear em chapa galvanizada e bebedouro automático contendo válvula acoplada ao copinho, na densidade de 2 aves/gaiola, sendo alimentadas à vontade, com a mesma ração de postura durante a fase de produção (Tabela 1). O programa de luz utilizado foi de 14 horas por dia logo após a transferência para o galpão de postura. A partir da semana seguinte, foram feitos acréscimos semanais de 15 minutos de luz/dia até atingir 16 horas de luz, permanecendo constante até o final do experimento.

As variáveis avaliadas foram idade das aves ao primeiro ovo (dias), porcentagem de postura (\%), consumo de ração (g/ave/dia), peso dos ovos (g), massa de ovos (g/ave/dia) e conversão alimentar (g/g).

Durante todo o período experimental, uma vez por semana, todos os ovos de cada parcela foram coletados, identificados e pesados em balança eletrônica (Marte) com precisão de 0,01 g. Desses ovos, foram selecionados três de 
cada parcela para avaliação da qualidade e das características dos ovos e determinação das porcentagens de gema, casca e albúmen (\%), das unidades Haugh e da gravidade específica.

Os dados foram analisados utilizando-se o procedimento ANOVA do SAS (2000) para um modelo fatorial e as médias comparadas pelo teste SNK a 5\% de probabilidade.

\section{Resultados e Discussão}

Na fase de crescimento, as médias das temperaturas máxima e mínima obtidas foram, respectivamente, $31,9^{\circ} \mathrm{C} \pm 1,75$ e $26,9^{\circ} \mathrm{C} \pm 1,78$ e a umidade relativa do ar de $78 \%$.

Não foram observadas interações $(\mathrm{P}>0,05)$ entre os fatores (linhagem e nível de FDN) para as variáveis de desempenho avaliadas (Tabela 2). Entretanto, o peso médio na 7a e 17므 semana, o ganho de peso total, o consumo de ração acumulado e a conversão alimentar variaram $(\mathrm{P}<0,05)$ entre as linhagens e o peso médio na 17ạ semana, o ganho de peso e a conversão alimentar foram influenciados $(\mathrm{P}<0,05)$ pelo nível de FDN.

Em relação às aves leves, as aves semipesadas apresentaram maior peso médio na 17ạ semana de idade, ganho de peso, consumo acumulado e melhor conversão alimentar. Essas diferenças no desempenho entre as linhagens se devem às características de crescimento impostas pelos programas de melhoramento genético utilizados na obtenção de cada linhagem. As poedeiras leves são selecionadas para menor peso corporal à maturidade e isso faz com que as aves leves apresentem menor ganho de peso e maior conversão alimentar em comparação às semipesadas durante a fase de crescimento. Por outro lado, por apresentarem maior peso corporal, as aves semipesadas consomem mais ração para atender às suas necessidades nutricionais, que são superiores às das aves leves, principalmente as de mantença (Neme et al., 2005). A melhor conversão alimentar das aves semipesadas se deve à sua maior taxa de ganho de peso durante esta fase do período de crescimento.

O nível de fibra da ração não influenciou $(\mathrm{P}>0,05)$ o consumo acumulado de ração das aves e, independentemente da linhagem, as aves alimentadas com menor nível de FDN apresentaram maior peso médio, maior ganho de peso e melhor conversão alimentar no final (17ํa semana) da fase de crescimento em relação às alimentadas com os demais níveis de fibra.

A redução no desempenho das frangas com o acréscimo de FDN na ração em níveis superiores a $14,50 \%$ pode ser associada aos efeitos prejudiciais do aumento da fração fibrosa da ração e às características da fração fibrosa do farelo de trigo, que foi utilizado para atingir os níveis de FDN testados.

O aumento do teor de fibra na ração prejudica a utilização dos nutrientes, uma vez que a fibra atua como barreira física, impedindo que as enzimas endógenas tenham acesso ao conteúdo interno das células vegetais, reduzindo os processos de digestão e absorção dos nutrientes (Jansen \& Carré, 1989). Por sua vez, o farelo de trigo é um ingrediente promotor do aumento da viscosidade intestinal, pois sua fração fibrosa é rica em polissacarídeos não-amídicos (PNA) solúveis, como as arabinoxilanas, que causam inibição geral da digestão dos alimentos, afetando a digestibilidade dos carboidratos, gorduras e proteínas. Esses efeitos podem

Tabela 2 - Desempenho de linhagens leves e semipesadas na fase de 7 a 17 semanas de idade alimentadas com dietas contendo diferentes níveis de fibra em detergente neutro (FDN)

\begin{tabular}{|c|c|c|c|c|c|}
\hline \multirow[t]{2}{*}{ Item } & \multicolumn{5}{|c|}{ Variável } \\
\hline & $\begin{array}{l}\text { Peso inicial } \\
\text { (g/ave) }\end{array}$ & $\begin{array}{l}\text { Peso final } \\
\text { (g/ave) }\end{array}$ & $\begin{array}{c}\text { Ganho de } \\
\text { peso (g/ave) }\end{array}$ & $\begin{array}{c}\text { Consumo acumulado } \\
\text { (g/ave) }\end{array}$ & $\begin{array}{c}\text { Conversão } \\
\text { alimentar (g/g) }\end{array}$ \\
\hline \multicolumn{6}{|l|}{ Nível de FDN (\%) } \\
\hline 14,50 & 526,11 & $1434,71 \mathrm{a}$ & $908,60 \mathrm{a}$ & 4438,53 & $4,90 \mathrm{~b}$ \\
\hline 16,50 & 526,95 & $1380,51 b$ & $853,56 b$ & 4419,20 & $5,19 a$ \\
\hline 18,50 & 525,85 & $1375,50 \mathrm{~b}$ & $849,65 b$ & 4365,58 & $5,15 a$ \\
\hline \multicolumn{6}{|l|}{ Linhagem } \\
\hline Leve & $520,27 b$ & $1339,89 b$ & $819,62 b$ & $4307,06 b$ & $5,26 a$ \\
\hline Semipesada & $532,34 a$ & $1453,93 a$ & $921,59 a$ & $4508,48 a$ & $4,90 \mathrm{~b}$ \\
\hline \multicolumn{6}{|l|}{ Efeito } \\
\hline Nível & ns & * & $*$ & ns & * \\
\hline Linhagem & $*$ & * & $*$ & $*$ & $*$ \\
\hline Nível $\times$ linhagem & ns & ns & ns & ns & ns \\
\hline Coeficiente de variação (\%) & 0,55 & 2,79 & 4,42 & 2,60 & 4,16 \\
\hline
\end{tabular}

Médias seguidas de letras minúsculas na coluna diferem entre si pelo teste SNK (5\%).

ns Não-significativo; * $(\mathrm{P}<0,05)$. 
alterar a morfologia e a fisiologia entérica, modificando a taxa de trânsito e desregulando a função hormonal, em virtude da variação na taxa de absorção de nutrientes (Araújo et al., 2008). Todos esses eventos certamente reduzem a taxa de crescimento e pioram a eficiência alimentar das aves alimentadas com maior proporção de FDN na ração.

Sobre os efeitos do aumento da fração fibrosa das rações sobre o consumo de ração das aves, tem sido relatado que a alta capacidade de absorção de água da fração solúvel contribui para a redução no consumo porque limita a ingestão de alimento devido ao volume ocupado no trato digestório (Rodríguez-Palenzuela et al., 1998) e à passagem mais lenta da digesta (Dunkley et al., 2007). Entretanto, nesta pesquisa, o consumo de ração acumulado foi semelhante para as rações com os diferentes níveis de fibra, sugerindo que o aumento até o nível de 18,50\% de FDN não promoveu alterações nas características da ração suficientes para comprometer o consumo de ração pelas frangas.

$\mathrm{Na}$ avaliação do desenvolvimento dos órgãos dos tratos digestório e reprodutor das aves (Tabela 3), não foram observadas interações $(P>0,05)$ entre linhagem e nível de fibra para as variáveis avaliadas.

As aves da linhagem leve apresentaram maior peso relativo do fígado e do ovário, menor peso relativo da moela e dos intestinos em relação às linhagens semipesadas. Essas diferenças no desenvolvimento dos órgãos do trato digestório e reprodutor entre as linhagens se devem às alterações nos aspectos fisiológicos das aves, decorrentes dos programas de melhoramento genético utilizados na obtenção de cada linhagem.

As poedeiras leves são selecionadas para menor peso corporal à maturidade e isso faz com que apresentem menor consumo de ração, de forma que este peso pode interferir no crescimento relativo dos órgãos do sistema digestório em relação ao apresentado pelas aves semipesadas. Por outro lado, por serem maiores, as aves semipesadas consomem mais ração para atender às necessidades nutricionais, o que favorecerá a atividade mecânica da moela e maior conteúdo do bolo alimentar no trato digestório dessas aves. Segundo Hazelwood et al. (1986), o fígado de poedeiras aumenta de peso nos períodos que antecedem a postura. Dessa forma, o maior peso relativo do fígado pode ser associado à precocidade das poedeiras leves, uma vez que o início da atividade reprodutiva da fêmea implica maior atividade desse órgão para a síntese do material da gema a ser depositado no ovário. O maior peso relativo do ovário das aves leves também sinaliza maior desenvolvimento desse órgão, possibilitando a essas aves o início da postura antes das semipesadas.

O nível de FDN da ração não influenciou $(\mathrm{P}>0,05)$ o tamanho do fígado, ovário e oviduto. Entretanto, independentemente da linhagem, as aves alimentadas com a dieta formulada com $14,50 \%$ de FDN apresentaram maior peso da moela, enquanto as alimentadas com $18,50 \%$ de FDN apresentaram maior peso dos intestinos.

O maior peso da moela com a ração com menor nível de FDN pode ter ocorrido em razão da necessidade de inclusão de areia lavada como inerte nessa ração para mantê-la isonutriente com as demais. Segundo Gonzáles-Alvarado et al. (2007), a influência da alimentação nas características da moela está associada à estimulação mecânica deste órgão, que depende do nível, do tipo de ingrediente, do tamanho e das características das partículas da ração. Assim, quanto mais estimulada for a atividade mecânica, maior será a moela.

O maior peso do intestino obtido com o maior nível de FDN na ração pode ser associado aos efeitos negativos da

Tabela 3 - Peso relativo dos órgãos de linhagens leves e semipesadas ao final da fase de crescimento (17ạ semana) alimentadas com dietas formuladas com três níveis de fibra em detergente neutro (FDN)

\begin{tabular}{|c|c|c|c|c|c|}
\hline \multirow[t]{2}{*}{ Item } & \multicolumn{5}{|c|}{ Variável } \\
\hline & Fígado (\%) & Moela (\%) & Intestinos (\%) & Ovário (\%) & Oviduto (\%) \\
\hline \multicolumn{6}{|l|}{ Nível de FDN (\%) } \\
\hline 16,50 & 2,17 & $1,98 b$ & $2,72 \mathrm{ab}$ & 0,15 & 1,45 \\
\hline 18,50 & 2,13 & $2,14 a b$ & $2,88^{\mathrm{a}}$ & 0,16 & 1,56 \\
\hline \multicolumn{6}{|l|}{ Linhagem } \\
\hline Leve & $2,48 a$ & $1,77 \mathrm{~b}$ & 2,77 & $0,18 \mathrm{a}$ & 1,53 \\
\hline \multicolumn{6}{|l|}{ Efeito } \\
\hline Nível & ns & $*$ & $*$ & ns & ns \\
\hline Linhagem & $*$ & * & ns & $*$ & ns \\
\hline Nível × linhagem & ns & ns & ns & ns & ns \\
\hline Coeficiente de variação (\%) & 10,45 & 7,87 & 6,33 & 37,20 & 12,36 \\
\hline
\end{tabular}

Médias seguidas de letras minúsculas na coluna diferem entre si pelo teste SNK (5\%).

ns Não-significativo; * $(\mathrm{P}<0,05)$ 
maior quantidade de fibra sobre a digestão e absorção de nutrientes. Esses efeitos induzem maior atividade desse órgão na tentativa de melhorar a digestão e a absorção com dietas de alta viscosidade, acarretando maior desenvolvimento dos órgãos.

Vários autores têm comentado que o aumento no peso relativo do trato gastrintestinal tem sido relacionado ao consumo de dietas fibrosas em outras espécies (frangos, ratos e suínos). Esses fatores podem estar relacionados tanto ao aumento da ingestão de fibras na ração quanto à baixa concentração calórica (Zhao et al., 1995; Jorgensen et al., 1996ab). Os resultados obtidos nessa pesquisa são semelhantes a essas indicações.

Durante a fase de produção, as médias das temperaturas mínimas e máximas foram $26,88^{\circ} \mathrm{C} \pm 1,37$ e $31,83^{\circ} \mathrm{C} \pm 1,25$, respectivamente, e umidade relativa do ar de $75 \%$.

Não foram observadas interações $(P>0,05)$ entre os fatores linhagem e nível de FDN para as características de desempenho avaliadas na fase de postura (Tabela 4). Também não foi observado efeito $(\mathrm{P}>0,05)$ dos níveis de FDN da ração oferecida às aves na fase de crescimento sobre esses mesmos parâmetros, contudo a idade das aves ao produzirem o primeiro ovo, o peso do ovo, a massa de ovo e a conversão alimentar variaram $(\mathrm{P}<0,05)$ entre as linhagens.

A idade ao primeiro ovo é um dado importante, pois caracteriza a maturidade sexual, que pode ser influenciada por diversos fatores envolvidos na criação das aves (Moro et al., 2002). Segundo Liu et al. (1995), o início da produção de ovos pode ser influenciado pela genética, idade cronológica e composição corporal das frangas, porém as características genéticas das linhagens exercem influência significativa na maturidade sexual, de forma que as aves leves normalmente são mais precoces que as semipesadas. Isso justifica a diferença no tempo para a produção do primeiro ovo entre as linhagens utilizadas nesta pesquisa. Por outro lado, ao final da fase de crescimento (17 semanas de idade), as aves da linhagem leve apresentavam maior desenvolvimento do fígado e ovário, fato que pode ser associado à maior atividade hormonal para o início da fase de postura nessas aves que são mais precoces.

Nas linhagens modernas, o início da postura deve ocorrer com peso corporal adequado, associado à idade cronológica. Segundo Leeson \& Summers (1997), as aves que apresentam maior peso corporal à maturidade sexual terão melhor desempenho e aquelas que estão com peso corporal baixo apresentarão maturidade mais tardia e pior desempenho. Nesse contexto, como as aves alimentadas com maior nível de fibra na ração (18,50\% de FDN) apresentaram menor peso corporal ao final da fase de crescimento, criou-se a expectativa de atraso na maturidade sexual dessas aves. Entretanto, a influência do nível de FDN da ração no peso corporal das frangas não foi suficiente para prejudicar significativamente a maturidade sexual das aves.

Ausência de influência das diferenças no peso corporal das frangas ao final da fase de crescimento sobre a maturidade sexual também foi relatada por Murakami et al. (1997) e Barros et al. (2006), que avaliaram a influência dos níveis de proteína da ração de crescimento sobre o desempenho nas fases de crescimento e postura. Entretanto, Araújo et al. (2008) verificaram que a redução no peso corporal das frangas, associada ao aumento da fibra na ração pela inclusão do farelo de trigo na ração de crescimento (7 a 19 semanas de idade), resultou em aumento na idade das

Tabela 4 - Desempenho de linhagens leves e semipesadas na fase de postura alimentadas na fase de 7 a 17 semanas de idade com dietas formuladas com três níveis de fibra em detergente neutro (FDN)

\begin{tabular}{|c|c|c|c|c|c|c|c|}
\hline \multirow{2}{*}{ Item } & \multicolumn{7}{|c|}{ Variável } \\
\hline & $\begin{array}{c}\text { Idade ao primeiro } \\
\text { ovo (dias) }\end{array}$ & $\begin{array}{c}\text { Consumo de } \\
\text { ração (g/ave/dia) }\end{array}$ & $\begin{array}{l}\text { Peso } \\
\text { final }(\mathrm{kg})\end{array}$ & $\begin{array}{l}\text { \%Postura } \\
\text { (ave/dia) }\end{array}$ & $\begin{array}{c}\text { Peso } \\
\text { ovo (g) }\end{array}$ & $\begin{array}{c}\text { Massa de ovos } \\
\text { (g/ave/dia) }\end{array}$ & $\begin{array}{l}\text { Conversão } \\
\text { alimentar (g/g) }\end{array}$ \\
\hline \multicolumn{8}{|l|}{ Nível de FDN (\%) } \\
\hline 14,50 & 122,63 & 98,67 & 1,60 & 95,42 & 58,02 & 55,39 & 1,72 \\
\hline 16,50 & 124,25 & 98,43 & 1,61 & 93,58 & 58,45 & 54,70 & 1,71 \\
\hline 18,50 & 126,75 & 99,50 & 1,60 & 94,88 & 58,21 & 55,24 & 1,72 \\
\hline \multicolumn{8}{|l|}{ Linhagem } \\
\hline Leve & $121,42 b$ & 97,70 & $1,55 b$ & 94,99 & $57,01 b$ & $54,18 b$ & $1,75 \mathrm{a}$ \\
\hline Semipesada & $126,67 a$ & 100,03 & $1,66 \mathrm{a}$ & 94,26 & $59,44 a$ & $56,05 a$ & $1,68 b$ \\
\hline \multicolumn{8}{|l|}{ Efeito } \\
\hline Nível & ns & ns & ns & ns & ns & ns & ns \\
\hline Linhagem & $*$ & ns & ns & ns & $*$ & $*$ & $*$ \\
\hline Nível × linhagem & ns & ns & $*$ & ns & ns & ns & ns \\
\hline Coeficiente de variação (\%) & 2,71 & 3,07 & 2,33 & 2,75 & 1,89 & 3,68 & 1,91 \\
\hline
\end{tabular}


aves ao primeiro ovo, que passou de 130 para 148 dias, em aves alimentadas com ração sem farelo de trigo e com $30 \%$ desse subproduto.

Considerando que as aves foram alimentadas com a mesma ração de postura, esperava-se que aquelas alimentadas com $14,50 \%$ de FDN, que eram mais pesadas ao final da fase de crescimento, apresentassem maior consumo de ração na fase de postura, visto que as exigências de mantença são maiores para aves mais pesadas (Neme et al., 2006). Barros et al. (2006) e Araújo et al. (2008) relataram que, embora os tratamentos influenciem significativamente o ganho de peso das frangas na fase de crescimento, o consumo de ração dessas aves na fase de postura não difere significativamente.

Embora seja esperada diferença entre o consumo de ração por poedeiras leves e semipesadas na fase de postura decorrente das exigências de mantença entre essas aves (Neme et al., 2006), durante a fase de postura, o consumo das linhagens utilizadas nessa pesquisa não diferiu significativamente. Entretanto, semelhança no consumo de ração dessas linhagens é observada quando se comparam os manuais de manejo, que relatam consumo variando de 105 a 115 (g/dia/ave) para aves leves e 110 a 115 (g/ave/dia) para aves semipesadas. A pequena diferença no peso corporal entre as linhagens estudadas ao início e final do período de postura também pode ter contribuído para o resultado nesta pesquisa.

Durante a fase de crescimento, o aumento do nível de FDN na ração contribuiu para que o peso corporal das aves no final dessa fase (17 semanas de idade) tenha sido menor. Todavia, essa diferença não se manteve durante o período de produção, visto que o peso corporal na 35a semana não diferiu entre os diferentes níveis de FDN utilizados. Esse resultado pode ser atribuído a um possível crescimento compensatório nas aves submetidas aos níveis mais elevados de fibra na ração. Assim, as aves podem ter sofrido restrição de nutrientes na fase de crescimento, mas, como a ração fornecida na fase de postura foi a mesma, tiveram a possibilidade de se recuperar. $\mathrm{O}$ fato de as aves poedeiras continuarem crescendo no início do ciclo de produção até atingirem a maturidade física também pode ter contribuído para a recuperação do peso. Sakomura et al. (2004) associaram ao crescimento compensatório a semelhança de peso na 35a semana de idade das aves que, em função do manejo alimentar, apresentaram diferenças de peso corporal ao final da fase de crescimento.

Independentemente do nível de FDN, o peso médio vivo das aves na 35a semana de idade foi menor nas aves leves em comparação às semipesadas. Contudo, as duas linhagens apresentaram pesos vivos, nessa idade, inferiores aos preconizados nos manuais das linhagens, sendo aproximadamente de $1.650 \mathrm{~g}$ para leves e $1.920 \mathrm{~g}$ para semipesadas. No entanto, tomando como base o peso final (17a semana) da fase de crescimento, para ambas as linhagens, o ganho de peso foi semelhante no final da fase de postura, sendo de aproximadamente $210 \mathrm{~g}$ para as aves leves e $206 \mathrm{~g}$ para as aves semipesadas.

Considerando que o peso corporal da franga ao final da fase de crescimento é um fator importante para o bom desempenho das poedeiras na fase de produção, esperavase que a influência do nível de fibra na ração sobre o peso corporal das frangas ao final da fase de crescimento tivesse reflexos sobre alguma das variáveis avaliadas na fase de postura. Entretanto, as diferenças no peso corporal das frangas na 17ạ semana de idade ocasionadas pelos níveis de FDN fornecidos na ração de crescimento não influenciaram a produção, o peso e a massa de ovos e a conversão alimentar durante a fase de postura.

Semelhante ao observado nesta pesquisa, Sakomura et al. (2004) e Barros et al. (2006) relataram que, embora os tratamentos tenham influenciado significativamente o ganho de peso das frangas na fase de crescimento, a produção, o peso e a massa de ovo e a conversão alimentar dessas aves na fase de postura não diferiram significativamente. Entretanto, Araújo et al. (2008) verificaram que a inclusão do farelo de trigo na ração de crescimento promoveu redução linear no ganho de peso das frangas e que as aves mais leves, ao final da fase de crescimento, apresentaram menor produção e massa de ovos e pior conversão alimentar na fase de postura.

Contudo, observando os dados da literatura, foi possível verificar que os efeitos da alimentação na fase de crescimento que resultaram em diferença entre 3 e $5 \%$ no peso corporal das frangas ao final desse período (Sakomura et al., 2004; Barros et al., 2006) podem ser compensados na fase subsequente, não afetando o desempenho no período total de produção. Por sua vez, Araújo et al. (2008) registraram diferenças de peso de $13 \%$ entre as frangas ao final da fase de crescimento e notaram que as aves mais leves apresentaram pior desempenho na fase de produção. Esses fatos podem justificar os resultados obtidos nesta pesquisa para o desempenho na fase de postura, visto que a maior diferença no peso das frangas ao final da fase de crescimento promovida pelo aumento da fibra na ração foi de $3 \%$ para as aves leves e de $5 \%$ para as aves semipesadas. Por outro lado, pode-se afirmar que, apesar do menor peso corporal ao final da fase de crescimento, as frangas alimentadas com ração com maior teor de fibra receberam, nessa fase, nutrientes suficientes para não comprometer o desempenho produtivo na fase de postura. 
As poedeiras semipesadas produziram ovos mais pesados, com maior massa, e tiveram melhor conversão alimentar em comparação às poedeiras leves. Considerando que todas as condições foram semelhantes entre as linhagens, a diferença no tamanho dos ovos se deve ao tamanho das aves, dada a correlação positiva entre o peso corporal da poedeira e o tamanho dos ovos produzidos. Por sua vez, o maior peso dos ovos contribuiu para maior massa de ovos das aves semipesadas, visto que a porcentagem de postura não variou significativamente entre as linhagens. Por outro lado, como o consumo de ração também não diferiu $(\mathrm{P}>0,05)$ entre as aves leves e semipesadas, obtevese melhor conversão alimentar para aves semipesadas, que produziram maior massa de ovos.

Não foram observadas interações $(P>0,05)$ nos constituintes e na qualidade dos ovos entre os fatores linhagem e nível de FDN sobre os componentes e a qualidade dos ovos (Tabela 5).

Assim como para as variáveis de desempenho na fase de postura, não foram observados efeitos $(\mathrm{P}>0,05)$ dos níveis de FDN da ração de crescimento sobre os constituintes e a qualidade dos ovos. Barros et al. (2006) também observaram que o efeito residual da alimentação recebida pelas frangas em crescimento não influenciou significativamente as porcentagens de gema, albúmen e casca e a gravidade específica dos ovos dessas aves. Araújo et al. (2008) não verificaram diferenças significativas na gravidade específica dos ovos produzidos pelas aves alimentadas com rações de crescimento com diferentes níveis de farelo de trigo.

Leeson \& Summers (1997) afirmaram que a proteína, os aminoácidos e o ácido linoleico são os fatores nutricionais mais importantes que afetam o peso do ovo e, consequentemente, a proporção dos componentes do ovo. Como neste estudo, as poedeiras receberam rações formuladas para conter níveis iguais de energia metabolizável, proteína bruta, cálcio, fósforo disponível, sódio, metionina e metionina + cistina, provavelmente os nutrientes ingeridos pelas aves foram suficientes para que os componentes e a qualidade dos ovos se mantivessem estáveis.

Na comparação entre as linhagens, observou-se que a porcentagem de casca não diferiu ( $\mathrm{P}>0,05)$, porém houve diferença $(\mathrm{P}<0,05)$ para a porcentagem de gema e albúmen. A maior porcentagem de gema foi obtida nos ovos das aves leves, enquanto a maior porcentagem de albúmen foi obtida nos ovos das aves semipesadas.

O peso do ovo incorpora três componentes: a gema, o albúmen e a casca. A proporção de cada componente está relacionada ao peso do ovo, que é determinada em sua maior parte pela linhagem, por meio dos resultados dos programas de melhoramento genético que visam aumentar o peso e a produção de ovos nos últimos anos (Akabar et al., 1983, citado por Carvalho et al., 2003).

O aumento do tamanho do ovo em aves de mesma idade pode ser seguido por redução na proporção de gema e casca e acréscimo na proporção do albúmen. Isso pode justificar os resultados obtidos para os ovos das aves semipesadas, que foram mais pesados que aqueles produzidos pelas aves leves.

As observações dos componentes dos ovos em função da linhagem são semelhantes às reportadas por Faria et al. (2007). Avaliando a porcentagem de gema e albúmen nas diferentes faixas etárias (25-26, 47-48 e 62-66 semanas de idade) de poedeiras leves (Lohmann LSL) e semipesadas (ISA Brown), esses autores observaram que a porcentagem

Tabela 5 - Componentes e qualidade dos ovos de poedeiras alimentadas com rações contendo diferentes níveis de fibra em detergente neutro (FDN) na fase de postura

\begin{tabular}{|c|c|c|c|c|c|}
\hline \multirow[t]{2}{*}{ Item } & \multicolumn{5}{|c|}{ Variável } \\
\hline & Gema (\%) & Albúmen (\%) & Casca $(\%)$ & Unidades Haugh & Gravidade específica \\
\hline \multicolumn{6}{|l|}{ Nível de FDN (\%) } \\
\hline 16,50 & 22,24 & 68,03 & 9,73 & 98,18 & 1,085 \\
\hline 18,50 & 23,09 & 67,02 & 9,90 & 98,05 & 1,083 \\
\hline \multicolumn{6}{|l|}{ Linhagem } \\
\hline \multicolumn{6}{|l|}{ Efeito } \\
\hline Nível & ns & ns & ns & ns & ns \\
\hline Linhagem & $*$ & $*$ & ns & $*$ & $*$ \\
\hline Nível $\times$ linhagem & ns & ns & ns & ns & ns \\
\hline CV (\%) & 6,94 & 2,47 & 7,70 & 0,50 & 0,61 \\
\hline
\end{tabular}

Médias seguidas de letras minúsculas na coluna diferem entre si pelo teste SNK (5\%).

ns Não-significativo; * $\mathrm{P}<0,05$. 
de gema foi maior nos ovos produzidos por poedeiras leves, porém a porcentagem de albúmen foi maior nos ovos produzidos por poedeiras semipesadas em todas as idades avaliadas.

Na avaliação da qualidade dos ovos, observou-se que as aves semipesadas produziram ovos com maior valor de unidades Haugh e menor gravidade específica em relação aos produzidos pelas aves leves.

A medida das unidades Haugh consiste em uma função logarítmica da altura do albúmen do ovo em relação ao seu peso e é o método mais utilizado para medir a qualidade interna dos ovos (Murakami et al., 2007). Entretanto, segundo Leandro et al. (2005), essa medida pode ser influenciada por diversos fatores como os ligados à ave (idade e genética), à nutrição (matériasprimas, microingredientes) e ao meio (manejo do ovo, temperatura e armazenamento). Portanto, comparando as linhagens, os ovos das aves semipesadas tiveram maiores valores de unidades Haugh por terem maior peso.

A gravidade específica dos ovos apresenta relação direta com o percentual de casca e a resistência à quebra, sendo utilizada como método indireto na determinação da qualidade da casca. Nesta pesquisa, foram observadas diferenças $(\mathrm{P}<0,05)$ entre os valores de gravidade específica obtidos para as duas linhagens. Os ovos das aves leves apresentaram melhor gravidade específica em comparação aos das aves semipesadas. Resultados semelhantes foram relatados por Albuquerque et al. (1999), que avaliaram ovos das linhagens Babcock (leve) e Hisex Brown (semipesada) e obtiveram melhores resultados para os ovos das aves leves. Entretanto, na literatura, podem ser encontrados resultados contrários.

\section{Conclusões}

O aumento do nível de fibra em detergente neutro na ração das frangas entre 7 e 17 semanas de idade reduz o ganho de peso e piora a conversão alimentar nessa fase, levando à obtenção de frangas menos pesadas ao final da fase de crescimento. O nível de fibra em detergente neutro na ração não influencia o desenvolvimento do sistema reprodutor, porém, no sistema digestório, o aumento do nível de FDN na ração resulta em aumento do tamanho relativo dos intestinos das frangas. As alterações no desempenho e no desenvolvimento dos órgãos do trato digestório promovidas pelo aumento da FDN na ração das frangas são semelhantes entre aves da linhagem leve e semipesada. Independentemente da linhagem, o aumento do nível de FDN das rações oferecidas para as frangas na fase de 7 a 17 semanas de idade até 18,50\% não influencia na maturidade sexual, no desempenho e na qualidade dos ovos dessas aves na fase de produção.

\section{Agradecimentos}

Ao Conselho Nacional de Desenvolvimento Científico e Tecnológico (CNPq), pelo apoio financeiro, à Hy-Line do Brasil, pela doação das aves, e a FORT DODGE Saúde Animal Ltda, pela doação das vacinas.

\section{Referências}

ALBUQUERQUE, R.; MENDONÇA, C.X.; GHION, E. et al. Efeito de diferentes métodos de descanso forçado sobre o desempenho de poedeiras. Brazilian Journal of Veterinary Research and Animal Science, v.36, n.3, p.153-163, 1999.

ARAÚJO, D.M.; SILVA, J.H.V. Enzimas exógenas em dietas contendo farelo de trigo e outros alimentos alternativos para aves: revisão. PUBVET, v.2, n.47, art. 453, 2008.

BARROS, L.R.; COSTA, F.G.P.; COSTA, J.S. et al. Níveis de proteína para frangas semipesadas no período de uma a dezoito semanas de idade. Ciência Animal Brasileira, v.7, n.2, p.131-141, 2006.

CARVALHO, F.B.; STRINGHINI, J.H.; JARDIM FILHO, R.M. e al. Influência da conservação e do período de armazenamento sobre a qualidade interna e da casca de ovos comerciais. Revista Brasileira de Ciência Avícola, Supl. 5, p.100, 2003.

DUNKLEY, K.D.; DUNKLEY, C.S.; NJONGMETA, N.L. Comparison of in vitro fermentation and molecular microbial profiles of high-fiber feed substrates incubated with chicken cecal inocula. Poultry Science, v.86, p.801-810, 2007.

FARIA D.E.; SILVA, F.H.A; RIZZO, M.F. et al. Sólidos totais e rendimento dos componentes dos ovos de poedeiras brancas e marrons. Acta Scientiarum Animal Sciences, v.29, n.2, p.173-177, 2007.

GONZÁLEZ-ALVARADO, J.M.; JIMÉNEZ-MORENO, E.; VALENCIA, D.G. et al. Effect of type of cereal, heat processing of the cereal, and inclusion of fiber in the diet on productive performance and digestive traits of broilers. Poultry Science, v.86, p.1705-1715, 2007.

HAZELWOOD, R.L. Carbohydrate metabolism. In: STURKIE, P.D. (Ed.) Avian physiology. New York: Spring-Verlag, 1986. p.303-325.

JANSSEN, W.M.M.A.; CARRÉ, B. Influence of fiber on digestibility of poultry feeds In: COLE, D.J.A.; HARESIGN, W. (Eds.) Recent developments in poultry nutrition. London: Butterworths, 1989. p.78-93.

JERACI, J.L.; VAN SOEST, P.J. Improved methods for analysis and biological characterization of fiber. Advances in experimental medicine and biology, v.270, p.245-263, 1990.

JORGENSEN, H.; ZHAO, X.-Q.; KNUDSEN, K.E.B. et al. The influence of dietary fiber source and level on the development of the gastrointestinal tract, digestibility and energy metabolism in broiler chickens. British Journal of Nutrition, v.75, p.379395, 1996a.

JORGENSEN, H.; ZHAO, X-Q.; EGGUM, B.O. The influence of dietary fibre and environmental temperature on the development of the gastrointestinal tract, digestibility, degree of fermentation in the hing-gut and energy metabolism in pigs. Journal of Nutrition, v.75, p.365-378, 1996 b.

LEANDRO, N.S.M.; DEUS, H.A.B.; STRINGHINI5, J.H. et al. Aspectos de qualidade interna e externa de ovos comercializados em diferentes estabelecimentos na região de Goiânia. Ciência Animal Brasileira, v.6, n.2, p.71-78, 2005. 
LEESON, S.; SUMMERS, J.D. Comercial poultry nutrition. 2.ed. Ontario: University Books, 1997. 350p.

LiU, G.; DUNNINGTON, E.A.; SIEGEL, P.B. Correlated responses to long-term divergent selection for eight-week body weight in chickens: growth, sexual maturity and egg production. Poultry Science, v.74, p.1259-1268, 1995.

MORO, M.E.G.; ARIKI, J.; MALHEIROS, E.B. Avaliação dos níveis de proteína da dieta sobre a idade à maturidade sexual e produção de ovos de perdiz (Rhynchotus rufescens Temminek). Acta Scientiarum, v.24, n.4, p.997-1000, 2002.

MURAKAMI, A.E.; KIRA, K.C.; OLIVEIRA, A.M. et al. Influência dos níveis protéicos na fase de cria e rescria de frangas de reposição sobre o desempenho produtivo na fase de produção. Revista Brasileira de Zootecnia, v.26, p.955-958, 1997.

MURAKAMI, A.E.; FERNANDES, J.I.M.; SAKAMOTO, M.I. et al. Efeito da suplementação enzimática no desempenho e qualidade dos ovos de poedeiras comerciais. Acta Scientiarum Animal Sciences, v.29, n.2, p.165-172, 2007.

NEME, R.; SAKOMURA, N.K.; FIALHO, F.B. et al. Modelling energy utilization for laying type pullets. Revista Brasileira Ciências Avícola, v.7, n.1, p.39-46, 2005.

NEME, R.; SAKOMURA, N.K; FUKAYAMA, E.H. et al. Curvas de crescimento e de deposição dos componentes corporais em aves de postura de diferentes linhagens. Revista Brasileira de Zootecnia, v.35, n.3, p.1091-1100, 2006.
RODRÍGUEZ-PALENZUELA, P.; GARCIA, J.; DE BLAS, C. Fibra soluble y su implicación en nutrición animal: enzimas y probióticos. In: Curso de Especialización FEDNA, 14., 1998, Barcelona. Palestras... Barcelona: FEDNA, 1998. p.229-239.

ROSTAGNO, H.S.; ALBINO, L.F.T.; DONZELE, J.L. et al. Tabelas brasileiras para aves e suínos: Composição de alimentos e exigências nutricionais. 2.ed. Viçosa, MG: UFV, 2005. 186p.

SAKOMURA, N.K.; ROSTAGNO, H.S. Métodos de pesquisa em nutrição de monogástricos. Jaboticabal: FUNEP, 2007. $283 p$.

SAKOMURA, N.K.; BENATTI, M.R.B.; BASAGLIA, R. et al. Avaliação de equações de predição de exigências energéticas na alimentação de frangas de postura. Revista Brasileira de Zootecnia, v.33, n.3, p.575-584, 2004.

SCHEIDELER, S.E.; JARONI, D.; PUTHPONGSIRIPRON, U. Strain, fiber source, and enzyme supplementation effects on pullet growth, nutrient utilization, gut morphology, and subsequent layer performance. Journal of Applied Poultry Research, v.7, p.359-371, 1998.

STATISTICAL ANALYSES SYSTEM - SAS. Users guide: statistics. Version 8. Cary: SAS Institute, 2000. v.2, 1452p.

ZHAO, X.; JORGENSEN, H.; EGGUM, B.O. The influence of dietary fibre on body composition, visceral organ weight, digestibility and energy balance in rats housed in different thermal environments. British Journal Nutrition, v.73, n.5, p.687-699, 1995. 